\title{
El derecho al cuidado: ¿Una nueva cuestión social ante los tribunales de justicia de Argentina?*
}

\author{
NATALIA GHERARDI Y CARLA ZIBECCHI
}

\section{Resumen}

En las últimas décadas el potencial del activismo judicial para la transformación de ciertas estructuras en la sociedad a través de las herramientas legales ha sido explorado en muchos países. En Argentina la incorporación del núcleo central de tratados de derechos humanos a la Constitución Nacional favoreció ese proceso y el avance en el reconocimiento de los derechos económicos y sociales. El artículo tiene como objetivo indagar qué condiciones posibilitan la politización del derecho y su movilización como un repertorio de la acción pública y por qué motivos esta estrategia ha sido poco explorada respecto de algunos derechos, como el derecho al cuidado. A partir del estudio de un caso pionero resuelto en Argentina sobre algunas de las problemáticas vinculadas con el cuidado de niños y niñas desde los 45 días de edad, el artículo abordará el rol que pueden desempeñar actores sociales con miras a la utilización de las estrategias legales para canalizar demandas relativas al derecho al cuidado.

PALABRAS CLAVE: derecho al cuidado; actores sociales; políticas públicas; estrategias legales; activismo judicial.

\begin{abstract}
In recent decades, the potential role of judicial activism in the transformation of certain social structures through the use of the law has been explored in a number of countries. In Argentina, the inclusion of principal human rights treaties to the National Constitution has encouraged that process as well as the promotion of social and economic rights. This article seeks to identify the conditions which enable the politicization of rights and to explain why these legal strategies have been seldom used with respect to certain rights, such as the right to care. Considering a pioneering case in the Argentine courts regarding some aspects of the right to care of children over 45 days of age, the article will explore the role that social actors may play through the use of legal strategies to channel demands for the right to care.
\end{abstract}

KEYWORDS: right to care; social actors; public policies; legal strategies; judicial activism.

* Nota del editor: La descripción del caso presentado en este artículo corresponde a la fines del año 2009, fecha en que fue recibido el artículo. 

$\mathrm{n}$ las últimas décadas numerosos países exploraron, en mayor o en menor medida, el potencial del activismo judicial para la transformación de ciertas estructuras en la sociedad a través de las herramientas legales ${ }^{1}$. Grupos de activistas, integrantes de círculos académicos y funcionarios han encontrado que el derecho puede brindar mecanismos idóneos y las cortes de justicia pueden constituirse en actores relevantes para que, grupos hasta entonces marginados, hagan escuchar sus reclamos. Esto ha producido una ampliación de los casos que tradicionalmente estaban circunscritos a decisiones políticas y que, en forma creciente, pasan a ser resueltos por medios judiciales o condicionados por decisiones judiciales.

Así, organizaciones no gubernamentales, facultades de derecho y agrupaciones de abogados y abogadas han profundizado el conocimiento del derecho de interés público ${ }^{2}$ y han promovido la especialización en su currículo de estudio ${ }^{3}$; las organizaciones donantes han fomentado el uso del derecho como herramienta de transformación social ${ }^{4}$; y diversas organizaciones locales encontraron incentivos para trabajar en esta área ${ }^{5}$. En Argentina el recurso al Poder Judicial buscó objetivos diversos. En algunas ocasiones se persiguió específicamente la transformación estructural de las instituciones o prácticas ilegítimas del Estado en áreas tales como las condiciones de encierro de las personas privadas de libertad ${ }^{6}$, el derecho a la vivienda ${ }^{7}$ o la educación ${ }^{8}$. En otros casos, fueron las demandas individuales las

1 La expresión "activismo judicial" comprende tanto el recurso estratégico a los tribunales por parte de organizaciones e instituciones dedicadas al litigio de interés público, como el mayor uso de los tribunales y las estrategias legales por parte de individuos para canalizar sus demandas al Estado o a otros particulares. Correlativamente, esto conlleva a la creciente disposición de los tribunales de justicia de aceptar ese rol de contralor respecto de los restantes poderes del Estado.

2 Sobre las dificultades para definir el "interés público" y los distintos enfoques para la conceptualización del derecho de interés público (en su concepción social, sustantiva y procesal), véase Rekosh (2005).

3 Se destaca la creación de un programa específico en la escuela de derecho de la New York University. En el ámbito local, siguiendo la tradición de algunas universidades anglosajonas, la Universidad de Palermo creó una Clínica Jurídica de Interés Público desde donde se iniciaron algunos de los casos más interesantes en cuanto a transformación legal, como el caso Fundación Mujeres en Igualdad c. Freddo S.A.

4 Ya en el año 2001 una publicación de la Fundación Ford daba cuenta de la incorporación del Poder Judicial como un actor relevante en la lucha por la vigencia de los derechos a través del financiamiento de proyectos vinculados al derecho que comenzó en los años 50 en Estados Unidos y se propagó a la región de América Latina en la década de 1970 (Fundación Ford, 2001).

5 Son varias las organizaciones de derechos humanos en Argentina que utilizaron y utilizan el derecho y, en particular, el litigio como estrategia de transformación social (por ejemplo, véase la recopilación de casos de derechos sociales impulsados por diversas organizaciones en Abramovich y Pautassi, 2009).

6 Caso "Verbitsky, Horacio s/habeas corpus", resuelto por la Corte Suprema de Justicia de la Nación el 3 de mayo de 2005.

7 Como ilustran algunos de los casos descritos en el trabajo de Maurino y Nino (2009).

8 También es interesante el caso "González de Delgado, Cristina y otros c. Universidad Nac. de Córdoba" resuelto por la Corte Suprema de Justicia de la Nación el 19 de septiembre de 2000, vinculado con la inscripción de mujeres en el Colegio Universitario Monserrat. Aunque el caso fue promovido por un grupo de padres que se oponían al ingreso de mujeres al tradicional establecimiento, la decisión de la Corte convalidó la reglamentación de la Universidad que admitía la inscripción de mujeres, reconociendo su derecho constitucional a recibir una educación en condiciones de igualdad con los varones. 
que buscaron la reparación de derechos vulnerados en áreas tales como la salud ${ }^{9}$ y la discriminación sexual ${ }^{10}$.

Sin dudas, es parte de la labor esencial del Poder Judicial interpretar las normas constitucionales, tanto en el ámbito federal como local. Sin embargo, recientemente, los derechos que se discuten en los tribunales de justicia, los actores que promueven estas acciones, los intereses que se representan, los procedimientos que se siguen y las decisiones que se adoptan, revelan una evolución incipiente pero promisoria hacia la configuración de un Poder Judicial comprometido con el acceso a la justicia de los grupos más desaventajados, garantizando la igualdad en el ejercicio de los derechos.

Esta mayor participación de los tribunales de justicia en la promoción de la plena vigencia de los derechos humanos se vincula con la consolidación de la corriente de opinión que sostiene que los derechos económicos, sociales y culturales (DESC) ${ }^{11}$ tienen el mismo origen, el mismo titular y el mismo destinatario que los derechos civiles y políticos. Superando la clásica posición que sostenía la distinción entre ambas "clases" de derechos con argumentos basados en su eficacia, exigibilidad y posibilidad de ser justiciable, en la actualidad ha tomado fuerza la concepción que sostiene que todos los derechos humanos son reclamables, indivisibles, interdependientes y universales. En consecuencia, el Estado se encuentra obligado a la promoción y protección de los derechos humanos en su integralidad, sin que corresponda hacer distinciones entre los derechos sociales y los derechos civiles y políticos ${ }^{12}$.

En Argentina la significativa cantidad de pronunciamientos judiciales en los que se hizo lugar a planteos vinculados con la violación de derechos sociales parece indicar que el desarrollo jurisprudencial se encamina por esa senda: la exigibilidad de estos derechos no se encuentra cuestionada en algunas jurisdicciones de Argentina, cuando menos, respecto de algunos derechos. En particular, los tribunales del fuero Contencioso Administrativo y Tributario de la ciudad de Buenos Aires han sido especialmente prolíficos en la recepción de estos planteos

9 Existe abundante jurisprudencia vinculada con el acceso a servicios de salud o a ciertas prestaciones, en ocasiones excluidas del Programa Médico Obligatorio (PMO) (véase una compilación en Courtis, 2006). Con respecto a los derechos sexuales y reproductivos, sin embargo, es notable la forma en que la judicialización de ciertos casos opera en detrimento de los derechos de las mujeres, como en el acceso al aborto no punible. Las mujeres se encuentran inmersas en un proceso judicial que las priva del ejercicio oportuno de sus derechos, por iniciativa o a instancias de los operadores de salud u operadores judiciales (Birgin y Gherardi, 2008).

10 Actualmente hay casos pendientes de resolución en la Corte Suprema de Justicia de la Nación vinculados al reconocimiento de pensiones por viudez a parejas homosexuales que, luego de la sanción de la Resolución $N^{\circ}$ 671/2008 de la ANSES, convalidó el derecho que ya había sido reconocido por algunos tribunales inferiores. Con respecto al casamiento entre personas del mismo sexo también hay casos pendientes de resolución ante distintos tribunales en el país.

11 En este trabajo nos referimos a los derechos económicos, sociales y culturales como "DESC" o como "derechos sociales", en forma indistinta.

12 Conf. Abramovich y Courtis (2002 y 2008). 
y en el desarrollo de respuestas novedosas ${ }^{13}$. Además, la incorporación del núcleo central de tratados de derechos humanos al plexo constitucional de la República Argentina (producto de la reforma de la Constitución Nacional de 1994) sin dudas favoreció ese proceso, generando un clima de incipiente confianza y con expectativas positivas respecto de la contribución esperable del Poder Judicial para avanzar en el reconocimiento de los derechos económicos y sociales.

Este artículo se propone revisar qué condiciones posibilitan la politización del derecho y su movilización como un repertorio de la acción pública y por qué motivos esta estrategia ha sido poco explorada respecto de algunos derechos que tienen un impacto particularmente importante en la vida y autonomía de las mujeres, como el derecho al cuidado.

A partir del análisis de un caso pionero iniciado por la Asociación Civil por la Igualdad y la Justicia (ACIJ) ${ }^{14}$ contra el Gobierno de la Ciudad de Buenos Aires $^{15}$, este artículo pone de manifiesto algunos aspectos novedosos del cuidado como derecho justiciable que el Gobierno de la Ciudad tiene la obligación de garantizar. En este caso, la interpretación del artículo 24 de la Constitución de la Ciudad Autónoma de Buenos Aires estuvo en el centro de la decisión judicial en la que se resolvió condenar al Estado local por la ausencia de una política que garantice la educación preinicial desde los 45 días de vida para todos sus habitantes. Sin embargo, a juzgar por las sentencias de primera instancia y de la Cámara de Apelaciones, la vinculación entre la educación preinicial e inicial y el cuidado se pusieron de manifiesto en algunos de los argumentos planteados por ACIJ, aunque éstos fueron escasamente recogidos por el discurso de los jueces.

13 Véanse los casos revelados en Abramovich y Pautassi (2009). Esta afirmación no implica que no haya habido casos trascendentes en otras jurisdicciones distintas de la ciudad de Buenos Aires, pero diversos motivos probablemente colaboraron para que el fuero Contencioso Administrativo y Tributario de la ciudad de Buenos Aires fuera particularmente receptivo a estos reclamos. Por lo pronto, se trata de un fuero que nace como consecuencia del reconocimiento de la autonomía de la ciudad, luego de la reforma de la Constitución Nacional de 1994 y, en consecuencia, todos los jueces y juezas fueron designados con posterioridad, jurando sobre la Constitución de la Ciudad, que específicamente protege y garantiza el ejercicio de los derechos sociales.

14 La Asociación Civil por la Igualdad y la Justicia (ACIJ) es una organización no partidaria, sin fines de lucro, dedicada a la defensa de los derechos de los grupos más desfavorecidos de la sociedad y el fortalecimiento de la democracia en Argentina. Fundada en 2002 por un grupo de abogados, ACIJ tiene por objetivos defender la efectiva vigencia de la Constitución Nacional y los principios del estado de derecho, promover el cumplimiento de las leyes que protegen a los grupos desaventajados y la erradicación de toda práctica discriminatoria, así como también contribuir al desarrollo de prácticas participativas y deliberativas de la democracia (véase www.acij.org.ar)

15 Se trata del fallo "Asociación Civil Por la Igualdad y la Justicia c/ GCBA s/ amparo (art. 14 CCABA)" Ciudad de Buenos Aires, resuelto a favor del planteo de ACIJ tanto en la sentencia de primera instancia (del 13 agosto de 2007) como en su posterior confirmación por la Cámara de Apelaciones (en marzo de 2008). Se trata de una sentencia no firme, actualmente pendiente de resolución por el Tribunal Superior de Justicia de la Ciudad de Buenos Aires. Para este trabajo no hemos realizado una investigación acabada sobre la jurisprudencia en distintas jurisdicciones de la Argentina vinculada con el tema que se aborda. El objetivo de este trabajo y la referencia al caso mencionado es a los fines expositivos, sin que ello signifique que no existan otras sentencias que desarrollan algunos de los argumentos que presentamos. 
El cuidado es concebido actualmente como una responsabilidad primaria de las familias que debe resolverse en el ámbito privado. En rigor, puede considerarse que en los últimos treinta años se ha intensificado el desplazamiento de ciertas prestaciones que antiguamente proveía el Estado hacia las personas, las familias y las redes sociales para satisfacer necesidades fundamentales de los hogares vinculados al cuidado intrageneracional (cuidado infantil y de adultos mayores) y de otros miembros dependientes (personas con discapacidades). Por otra parte, en términos normativos, Argentina restringe la protección del derecho al cuidado a la madre trabajadora (asalariadas registradas) dejando excluidos a grandes sectores de la población, tales como trabajadoras no registradas, informales, y trabajadoras del servicio doméstico. El deterioro generalizado de servicios y políticas públicas pone en evidencia los conflictos que deben enfrentar las familias para garantizar la permanencia de sus integrantes en el mercado laboral, a la luz de la carga de responsabilidades familiares. Al mismo tiempo, el derecho al cuidado -en tanto un derecho universal- da cuenta de la necesidad imperiosa de la implementación de políticas activas de intervención.

La producción académica y la literatura específica han explorado la problemática de la provisión del cuidado desde múltiples aristas. En este sentido, pueden encontrarse enfoques provenientes de la economía feminista -la "economía del cuidado"-, aproximaciones desde el enfoque de derechos y también desde el debate vinculado a la conciliación trabajo y familia. Sin embargo, las deudas pendientes en materia legislativa y de políticas públicas en torno al cuidado o las escasas prestaciones del Estado orientadas a satisfacer las necesidades de cuidado, no han sido en general exploradas por las organizaciones y activistas que sí recurrieron a estrategias judiciales en relación con otros temas.

Este artículo presenta, en primer lugar, una breve conceptualización del cuidado en tanto problemática social desde diversos enfoques teóricos. Luego se describen los principales déficits existentes en torno a la infraestructura y servicios de cuidados que permiten articular responsabilidades laborales y familiares. El análisis se realiza en base a indicadores sociodemográficos, datos estadísticos disponibles y estudios efectuados por expertos y expertas en la materia. En segundo término, y a partir del estudio del caso planteado por ACIJ contra el Gobierno de la Ciudad de Buenos Aires, el artículo propone abordar el rol que pueden desempeñar diversos actores sociales dedicados al litigio de interés público con miras a la utilización de las estrategias legales para canalizar demandas relativas al derecho al cuidado. En particular, se avanza en torno a la capacidad potencial de los diversos actores del ámbito laboral y la sociedad civil para constituirse como agentes relevantes con el objeto de establecer reclamos vinculados con el acceso al derecho al cuidado, tanto en términos de infraestructura como de servicios y medidas legales que brinden protección.

Aun cuando el cuidado no se restringe a la atención que demandan niños y niñas pequeños, el caso iniciado por ACIJ objeto de este análisis (por su valor discursivo, por la claridad de los derechos violados) servirá como punto de partida para la revisión del potencial del activismo judicial en la promoción del derecho 
El derecho al cuidado: ¿Una nueva cuestión social ante los tribunales de justicia...

al cuidado. Sin embargo, las reflexiones sobre el cuidado como derecho deben extenderse a todos sus ámbitos.

\section{El cuidado: múltiples enfoques teóricos}

En los últimos años el debate en torno al "cuidado" ha cobrado un interesante dinamismo. En términos concretos, se observa una profusa literatura que aborda el concepto del "cuidado" en toda su complejidad, señalando las múltiples dimensiones que lo componen. A grandes rasgos, estos estudios destacan el trabajo material que demanda el acto de cuidar, el costo económico que conlleva y la dimensión afectiva que implica. Asimismo, se destaca cómo los ciclos vitales (niñez y ancianidad), en los cuales las personas más necesitan de cuidados especiales, han sido históricamente objeto de análisis y regulaciones en materia de políticas públicas.

Más específicamente, en relación con la actividad de "cuidado" se reconocen dos tipos: el cuidado directo, que implica la prestación material del mismo, la atención de las necesidades físicas, biológicas y afectivas de tal manera que supone una transferencia de tiempo y una interacción "cara a cara" entre las personas que otorgan y reciben el cuidado; y el cuidado indirecto, que consiste en la transferencia desde un componente de algún sistema social, especializado o no, de los mecanismos necesarios para que los individuos generen por cuenta propia las atenciones que requieren (Marco, 2007). Asimismo, algunas autoras feministas destacan que la diferencia entre "cuidado" y "servicios personales" no reside en la naturaleza del acto, ni en la relación de intimidad del trabajo de cuidado, sino en la facultad de mando de una de las partes y la falta de autonomía de la otra -es decir, en su carácter asimétrico- (Tronto, 2006). La literatura feminista también ha demostrado cómo las personas -en especial las madres proveedoras de cuidado- entablan una relación muy particular con aquellas personas dependientes de ese cuidado y protección, y cómo la misma es reforzada por un conjunto de normas sociales (Folbre, 2001).

Al calor de este debate se encuentra el aporte de las economistas que utilizan el concepto de "economía del cuidado" para referirse a un espacio bastante indefinido de bienes, servicios, actividades, relaciones y valores relativos a las necesidades más básicas requeridas para la existencia y reproducción de las personas. En esta dirección, Rodríguez Enríquez (2005) desarrolla distintas aproximaciones a la economía del cuidado: una de ellas se asocia a la idea de "trabajo de cuidado no remunerado", realizado en el ámbito del hogar. En otros casos, la idea de economía del cuidado es extendida al concepto de reproducción social. Desde esta concepción se refiere al espacio donde la fuerza de trabajo es reproducida, incluyendo todas las actividades necesarias ${ }^{16}$. Como resultado de ambas aproximaciones, Rodríguez Enríquez señala la importancia de asociar el trabajo doméstico con la idea de reproducción social, lo cual no implica, necesariamente, que 
la reproducción social se limita a ellos, sino que el trabajo doméstico es el núcleo central de ese proceso (es decir, puede complementarse con trabajo asalariado en el hogar o de servicios, pero la responsabilidad última sigue recayendo sobre el trabajo familiar no remunerado). De allí que dicha autora propone un concepto de "economía de cuidado ampliada" para referirse tanto al sistema de reproducción social, el trabajo doméstico no remunerado realizado en el interior de los hogares, como al sistema de provisión pública (educación pública, salud pública, servicios de cuidado infantil, cuidado a personas mayores, etc.) y privada (oferta de trabajo doméstico y servicios de educación y salud privados) de los servicios de cuidado. Así, la autora señala que ambas esferas están íntimamente relacionadas y presentan múltiples dimensiones que determinan sus particulares características: (i) se trata de actividades que dependen de manera muy importante de las relaciones interpersonales que se establecen entre el proveedor del bien o servicio de cuidado y el que recibe el cuidado; (ii) existe la creencia extendida -y errónea- de que las mujeres están naturalmente mejor dotadas para llevarlas adelante; y (iii) este proceso de especialización de las mujeres en las tareas de cuidado va íntimamente ligado con la separación de las esferas de la producción y reproducción, y con la consecuente exclusión y segregación de las mujeres en el mercado de empleo.

Otro ángulo desde donde se encara la problemática del cuidado es el que desarrollan los trabajos que han abordado el conflicto familia y trabajo y que refiere al estudio de las mal denominadas "políticas de conciliación familia y trabajo"17. En líneas generales, esta literatura destaca, en primer término, que uno de los resultados no previstos de las políticas de conciliación ha sido que sólo han servido para que concilien las mujeres, reforzando la idea sobre la responsabilidad femenina del cuidado intrageneracional, con una muy escasa participación de los varones (Astelarra, 200518 y Torns Martin, 2005). En segundo lugar, se han estudiado las consecuencias negativas de los conflictos de trabajo y familia: mayores

16 De allí, como veremos más adelante, que es muy importante analizar el contexto histórico en el cual se realiza: "... a ellas (a las mujeres) se les exige que compensen las insuficiencias de los servicios públicos y los efectos destructivos del mercado laboral. Cuanto más encubiertos son estos efectos, más importante es el papel de la familia como lugar donde se descargan las tensiones y las inseguridades de sus componentes" (Picchio, 1994: 456).

17 Las primeras políticas de conciliación a nivel mundial fueron las que se denominaron como family friendly policies, su objetivo principal fue la incorporación de la familia y el cuidado como un área que requiere medidas para que sea posible la igualdad laboral de las mujeres. De alli que surge la denominación de políticas de conciliación laboral/familiar (fundamentalmente permisos de maternidad/ paternidad y la provisión de servicios de cuidado) (Astelarra, 2005).

18 "De hecho, el propio concepto de conciliación surge del mercado de trabajo si se revisa su historia. La conciliación como un proceso se refería a la mediación entre dos grupos contrarios en el mercado laboral. Los interlocutores en esta conciliación fueron los sindicatos y las organizaciones empresariales o, en el caso individual de una empresa, sus trabajadores y su dirección. Sin embargo, cuando se aplica al ámbito familiar se trata de un espacio en el que no se supone que haya contrarios ni opuestos y que, además, se presume que es armónico. Hay que agregar que el mundo familiar no tiene reconocida ni negociación colectiva ni agentes sociales en conflicto. Por lo tanto, lo único que se puede producir allí es una negociación individual entre personas" (Astelarra, 2005: 9). 
riesgos de deterioro de salud para padres que trabajan, un mal desempeño de las funciones parentales, tensión psicológica, ansiedad, irritación, estrés y diversos problemas sintomáticos (Frone, Russell y Cooper, 1992). Finalmente, se observa que el conflicto familia y trabajo se produce en tanto existe una clara concentración temporal del trabajo entre lo que se denomina la edad más productiva de varones y mujeres en el mercado laboral (25-45 años) que coincide, precisamente, con las mayores responsabilidades familiares que surgen a partir de la formación de las familias, el cuidado de hijos pequeños y, en algunos casos, el cuidado de los adultos mayores (Arriagada, 2004).

Cómo valorar el trabajo de cuidado que realizan mayoritariamente las mujeres sin entramparlas en este rol de cuidadoras del ámbito privado y sin reforzar su exclusión de la esfera pública, constituye otro dilema vigente y contemporáneo en los estudios académicos. Frente a esta disyuntiva se han dado distintas respuestas que ponen en juego la problemática del vínculo entre la ética del cuidado y la justicia. Lister, por ejemplo, plantea que es necesario considerar una ética de cuidado y otra de justicia o de derechos. Es decir, según la autora, la comprensión de la ciudadanía puede ser enriquecida por una ética del cuidado, mientras que la práctica del cuidado debe ser garantizada por una ética de derechos. En un nivel más práctico, Lister plantea la importancia de una distribución más justa entre varones y mujeres -algo que no está totalmente libre de problemas- y una distribución, también más justa, entre familias individuales y la sociedad más amplia (por ejemplo, a través de políticas públicas mejor financiadas) (Lister, 1995). Pautassi, desde otro enfoque, destaca la importancia de considerar el derecho a ser cuidado y a cuidarse como un derecho universal, siendo necesario para su cumplimiento no sólo la promoción de una oferta de cuidado sino también la universalización de la responsabilidad, la tarea y la asignación de los recursos materiales para realizarlo. En este sentido, esta autora considera que incorporar una lógica de derechos a la complejidad del cuidado no sólo permitiría el reconocimiento de la tarea sino también una mejora sustancial en la calidad de vida ciudadana. Para ello, dice la autora, es importante dejar de lado la "ética" -que sólo refuerza el carácter altruista adjudicado a las mujeres- para hablar de un "derecho" al cuidado (Pautassi, 2007). No se trata de la "lucha" de una parte de la sociedad por mejorar las condiciones en las que se realizan las tareas de cuidado, sino del reconocimiento de un derecho universal e inalienable a cuidar, ser cuidado y a cuidarse. Éste será un primer paso para distribuir las responsabilidades de cuidado entre todos los miembros de la sociedad y no depositarlas sólo en las mujeres.

La conceptualización del cuidado como derecho conlleva para el Estado, naturalmente, no sólo obligaciones negativas (abstenerse de entorpecer los servicios de guarderías infantiles, no impedir el acceso de un adulto mayor al sistema de salud) sino también obligaciones positivas, tales como proveer los medios para poder cuidar y garantizar que el cuidado se lleve adelante en condiciones de igualdad: "En todos los casos, debe quedar claro que existen sujetos obligados a proveer el cuidado, desde los miembros de la pareja para con sus 
hijos, o de los hijos varones y mujeres para con sus progenitores en situación de autonomía relativa, pero también es el Estado o los particulares en determinados casos quienes también se encuentran obligados a 'hacer' en materia de cuidado" (Pautassi, 2007: 19).

\section{Las (ausentes) aplicaciones del concepto de cuidado}

\subsection{POLÍTICAS PÚBLICAS Y PROVISIÓN DE CUIDADO}

Dado el estrecho vínculo entre Estado, mercado y familia, las políticas públicas pueden favorecer u obstaculizar distintas conductas de las personas, entre ellas, la participación de la mujer en el mercado laboral o su permanencia en el hogar y pueden modificar profundamente la combinación entre el trabajo productivo y el trabajo de cuidado. En este sentido, el ajuste de los presupuestos públicos impuso un contexto crítico para la organización del cuidado. En particular, en los últimos treinta años, la ausencia o deterioro generalizado de las políticas públicas de cuidado determinó que la resolución del conflicto entre las responsabilidades derivadas de la familia y del trabajo variara enormemente por nivel socioeconómico de pertenencia y según el género ${ }^{19}$.

En el caso de las poblaciones más vulnerables, se produce de esta manera un círculo vicioso de la pobreza: los hogares que pueden afrontar el costo de contratar servicios de cuidado privados tienen más posibilidades para elegir la combinación de trabajos y responsabilidades entre los miembros. Por el contrario, los hogares de bajos ingresos no pueden contratar servicios de cuidado privados, lo cual produce frecuentemente que la mujer de escasos recursos no se inserte en el mercado laboral o tenga una trayectoria laboral intermitente y precaria. La primera consecuencia de que las mujeres sean las principales encargadas del cuidado y del trabajo doméstico no remunerado reside en que la presencia de niños y niñas en el hogar aparece como un condicionante para la participación económica femenina ${ }^{20}$.

19 En la mayoría de los países de América Latina las reformas estructurales y los procesos de ajuste social, llevados a cabo particularmente durante la década de los años noventa, dio cuenta de un contexto caracterizado por crecientes dificultades socioeconómicas y alta flexibilización y precarización de las condiciones contractuales laborales, lo que hace suponer que son muy pocas las mujeres trabajadoras que efectivamente cuentan con beneficios de cuidado infantil. Para el resto, queda en manos de las propias mujeres y, en el mejor de los casos, de sus familias la posibilidad de contratar servicios de cuidado infantil en el mercado, o asegurarlos mediante apoyo de relaciones de amistad u otras redes sociales (por ejemplo, organizaciones comunitarias).

20 Esto se puede observar en el caso de la tasa de actividad de las mujeres que tienen hijos menores, que es más baja que la de las mujeres que no los tienen. Las mujeres que no tienen hijos a cargo no han disminuido significativamente su participación económica en el periodo comprendido entre los años 20032006. No obstante, se observa un comportamiento diferencial por parte de las mujeres que tienen hijas e hijos pequeños, que han visto disminuida su tasa de actividad económica, tendencia que se agudiza a medida que aumenta el número de hijos (ELA, 2009). 
Un estudio realizado por la organización no gubernamental ELA -Equipo Latinoamericano de Justicia y Género- ${ }^{21}$ en los tres principales aglomerados urbanos del país, ha detectado las siguientes situaciones que reflejan, a grandes rasgos, las estrategias utilizadas para la articulación entre familia y trabajo. Ante la ausencia generalizada de guarderías y jardines maternales de las empresas donde se desempeñan las trabajadoras, la estrategia de cuidado más utilizada por las mujeres encuestadas son las instituciones educativas (guardería, jardín maternal y escuela) cercanas al hogar, seguida por el recurso a las redes de parentesco y/u otro/a miembro del hogar (recursos más habituales que el servicio doméstico remunerado $\mathrm{u}$ otras formas de cuidado). El mismo estudio revela un dato alarmante: en el Gran Buenos Aires el 5\% de los menores de 14 años quedan solos mientras sus progenitores trabajan (ELA, 2007) ${ }^{22}$.

En términos normativos, Argentina restringe sus intervenciones en torno al cuidado en dos esferas que, a grandes rasgos, pueden ser diferenciadas: la protección a la madre trabajadora en el régimen laboral (fundamentalmente en el periodo de gestación, alumbramiento y lactancia) ${ }^{23}$ y la obligatoriedad de la educación básica.

Claramente, en tanto la regulación del cuidado desde las normas laborales se restringe a las trabajadoras formales asalariadas, uno de sus principales déficits es la exclusión de un gran contingente de trabajadores/as para los cuales no existe ningún tipo de protección y cobertura ${ }^{24}$.

En lo que respecta a la segunda esfera, esto es, tanto el caso de las guarderías como de los servicios educativos para los niños y niñas más pequeños, existe una oferta estatal insuficiente e inadecuada, caracterizada por una provisión exigua de guarderías y jardines de infantes y con una jornada escolar tan reducida que resulta incompatible con la laboral; a lo que se suma una escasa oferta de hogares y centros de día para adultos mayores (Rodríguez Enríquez, 2005).

Para un importante sector de la población, la articulación de responsabilidades de cuidado con responsabilidades laborales implica un problema de magnitud, en particular para aquellas personas que no se encuentran protegidas por las normas laborales. El desinterés del Estado por la implementación de políticas públicas en materia de cuidado esconde serias consecuencias: por un lado, los cos-

21 ELA es una organización no gubernamental argentina, que trabaja para mejorar la situación social, política y económica de las mujeres, promoviendo el pleno ejercicio de sus derechos mediante las políticas públicas y el acceso a la justicia (véase www.ela.org.ar). El trabajo de campo de la encuesta referida se llevó a cabo entre el 7 de marzo y el 18 de abril de 2006. La muestra de 1.600 casos representa a las mujeres de entre 18 y 69 años, residentes en los tres principales aglomerados urbanos del país: área Metropolitana, Gran Córdoba y Gran Rosario.

22 En la ciudad de Rosario esta estrategia de cuidado bajo responsabilidad de otro miembro del hogar es superior inclusive a la escuela/jardín/guardería (ELA, 2007).

23 Para un análisis completo sobre cómo la normativa laboral contribuye al sostenimiento del modelo familiar según el cual es a las mujeres a quienes competen las responsabilidades del cuidado de la familia, véase: Pautassi et al. (2004).

24 Para nombrar sólo algunos: trabajadores/as en situación de precariedad laboral (sin aportes al sistema de seguridad social), trabajadores/as informales, migrantes en condiciones irregulares, empleadas del servicio doméstico, beneficiarios/as de programas sociales, entre otros. 
tos que enfrentan y sufren las personas -en su mayoría mujeres- que asumen la responsabilidad de cuidar, son muy difíciles de cuantificar. Por otro lado, tampoco existen formas de evaluar -y por lo tanto valorizar- el servicio de cuidado intrageneracional (esto es, cuidado infantil y cuidado de los adultos mayores) que se está brindando en el país.

\subsection{LA SITUACIÓN DE CUIDADO INTRAGENERACIONAL EN ARGENTINA: SESGOS, DÉFICITS Y VACÍOS EXISTENTES}

\section{El cuidado de niños y niñas}

Las intervenciones estatales dedicadas al cuidado de niños y niñas se restringen a tres grandes acciones: las que se vinculan con el sistema educativo (en especial jardines maternales y guarderías para la primera infancia y educación formal del nivel primario); el programa de asignaciones familiares; y los programas sociales que distribuyen bienes o servicios relativos al cuidado de los niños y niñas (la mayoría de ellos basados en un enfoque asistencialista).

Frecuentemente se ha señalado el rol fundamental que desempeña el nivel preinicial e inicial en la primera infancia en relación con la socialización de la progenie, el cuidado y su incidencia en el desarrollo educativo posterior. Son numerosos los estudios que han demostrado que los niños y niñas que acceden a una escolarización temprana tienen mejores posibilidades de desempeño en la escuela primaria y en el desarrollo educativo posterior. Sin embargo, históricamente en Argentina, el nivel preinicial tuvo un desarrollo mucho más desigual que el nivel siguiente. Se trata de una oferta educativa básicamente urbana en la cual la iniciativa privada tiene un peso relevante en claro perjuicio de los sectores económicos más desaventajados. En consecuencia, el desarrollo de este nivel preinicial históricamente ha beneficiado a los sectores urbanos más favorecidos, quienes ven reforzadas sus probabilidades de éxito en el resto de la carrera escolar (Tenti Fanfani, 1995).

Frente a todas las evidencias en torno a las potencialidades que tiene dicho ciclo en materia de cuidado y desempeño educativo posterior, investigaciones recientes han constatado la falta de oferta estatal tanto en el caso de las guarderías como de los servicios educativos para los niños y niñas más pequeños. Mientras que los jardines de infantes que están integrados plenamente al sistema educativo sólo atienden a la población infantil entre los 3 y 5 años, las guarderías o jardines maternales, que atienden a niños entre los 0 y los 2 años, se han desarrollado sólo desde una función asistencial, desestimando su importancia pedagógica y su papel en la organización de los hogares (Rodríguez Enríquez, 2007).

Si bien en los últimos años se extendió la obligatoriedad de la educación en el nivel inicial, ampliándose significativamente la oferta y la cobertura del sistema educativo, la importancia de esta política está limitada ya que son pocos los es- 
tablecimientos escolares de doble jornada y la presencia de la gestión privada en este tipo de oferta es notoriamente mayor a la pública ${ }^{25}$.

Por ejemplo, en el caso de la Ciudad Autónoma de Buenos Aires (CABA) existen 720 establecimientos educativos donde se brinda educación del nivel inicial -común y especial. De ese total la oferta pública estatal representa sólo el 32\%. Si se analiza la edad de los alumnos según su asistencia a un establecimiento público y privado, se observa que en caso de los niños y niñas menores de 2 años existe una diferencia leve entre quienes asisten a establecimientos del sector privado y del sector público. Sin embargo, a partir de los 2 años la brecha entre las matrículas de instituciones privadas y públicas se amplía a favor de las primeras. Desde la edad de escolaridad obligatoria (5 años y más) aumenta el número total de matriculados y, al mismo tiempo, se reduce nuevamente la brecha entre los niños y niñas que asisten a instituciones educativas públicas o privadas. Sin embargo, en todas las edades la matrícula del sector privado supera a la del ámbito público (ELA, 2009).

Un déficit que presenta el servicio educativo argentino en vistas a aliviar las tensiones entre la vida familiar y laboral reside en la baja oferta de escuelas con doble jornada escolar en el sector público. Al igual que lo que ocurre con el nivel preinicial, la matrícula mayoritaria para el sector inicial, tanto en el sector estatal como en el privado, se concentra en los turnos de media jornada (mañana o tarde), mientras que la jornada doble representa el 2,3\% en el sector estatal y el $1,8 \%$ en el sector privado. Para el nivel primario, tanto de gestión estatal como privada, la oferta de doble jornada representa apenas alrededor del 5,5\% de la cobertura total (Rodríguez Enríquez, 2007).

El límite al que se enfrenta la cobertura del sistema educativo en edades tempranas tiene importantes consecuencias para las familias de los estratos socioeconómicos más modestos. A pesar de las garantías previstas en la Constitución de la Ciudad de Buenos Aires, el déficit que se registra en la Ciudad entre el reconocimiento normativo y la praxis cotidiana de ejercicio de los derechos es tan evidente, que quedó claramente de manifiesto ante los tribunales de justicia en el caso impulsado exitosamente por ACIJ.

Por otra parte, Argentina cuenta con el sistema de asignaciones familiares que forma parte del salario indirecto. Son prestaciones en dinero, de carácter no remunerativo, cuyo pago se encuentra sujeto al cumplimiento de determinadas condiciones que varían según la prestación de que se trate. En rigor, las asignaciones familiares se circunscriben a asalariados formales y funcionan bajo una lógica de seguro social, quedando excluidos de su percepción aquellos sectores pertenecientes a la economía informal, cuentapropistas, autónomos o monotributistas, desempleados no receptores del seguro de desempleo (por ejemplo quienes reciben programas de transferencias de ingresos condicionados) y trabajadoras del servicio doméstico, entre otras categorías (CELS, 2007).

25 La debilidad de las políticas de cuidado se refleja en los sistemas estadísticos y los vacíos de información: son escasos los datos sobre la existencia de guarderías y jardines maternales, el nivel de asistencia y cobertura, como también lo son en relación con los recursos estatales destinados a la infancia. 
De un modo similar a aquellas políticas de conciliación familia y trabajo que se circunscriben al trabajo formal asalariado, el sistema de asignaciones familiares continúa poniendo el acento en el sector asalariado formal, dejando por fuera a amplios sectores de la población. En este sentido es importante considerar que, de acuerdo con la cantidad de niños/as establecida en el último Censo Nacional de Población (2001), más del 70\% de los niños de Argentina no son cubiertos por esta política, dando lugar a fuertes situaciones de discriminación entre niños/as según el estatus laboral de sus progenitores ${ }^{26}$.

En materia de políticas sociales para la niñez, Argentina concentra su accionar en dos focos: por un lado, a través de programas nutricionales y de atención médica de embarazadas, madres y niño/as, es decir, políticas que atienden el binomio "madre e hijo" 27 . Por otro lado, en programas de transferencias de ingresos condicionados, como el Plan Jefes y Jefas de Hogar y el Programa Familias ${ }^{28}$. En rigor, la presencia de hijos/as menores es lo que posibilita a un hogar acceder a estos programas de transferencia de ingresos y asigna a la mujer en calidad de "titular" del beneficio por hijo/a. Se trata de programas sociales que se caracterizan tanto por introducir una mayor corresponsabilidad a las madres en situación de pobreza (transferencia de ingresos condicionados a contraprestaciones laborales y/o condicionalidades en salud y educación), como por no incorporar ninguna medida que facilite el cuidado de los/as hijos/as menores y la incorporación de estas mujeres al mercado laboral.

Al mismo tiempo, estos programas refuerzan la idea de que el cuidado es una responsabilidad individual (no social) de las mujeres (no compartida con los progenitores varones). A su vez, conllevan situaciones estigmatizantes para las madres en situación de pobreza, pues deben "certificar" las condicionalidades en salud y educación, sin garantías respecto de la existencia de las instancias institucionales adecuadas para que puedan efectuar los controles en salud y educación que el programa les impone (Zibecchi, 2008) ${ }^{29}$.

26 Por ejemplo, un hijo de una madre titular de programas sociales de transferencias de ingresos como el Programa Familias, recibe por este concepto 30 pesos, mientras que si el/la niño/a tiene a alguno de sus progenitores con un trabajo formal asalariado puede llegar a percibir hasta 100 pesos por asignaciones familiares. Estos elementos entran en tensión con la concepción de universalidad que establece la Convención Internacional de los Derechos del Niño, que no permite hacer distinción entre las personas menores de edad. Por otro lado, aquellas políticas públicas que se implementen deben tener en vista el interés superior del niño, que es quien debe primar como titular de derechos (CELS, 2007).

27 Por ejemplo, el Programa Materno Infantil (PROMIN), el Plan Nacer, el Programa Nacional de Desarrollo Infantil Primeros Años, dependientes de la Dirección Nacional de Maternidad e Infancia del Ministerio de Salud de la Nación (http://www.msal.gov.ar/htm/Site/promin/UCMISALUD/index.htm). A nivel provincial existen otros programas de similar naturaleza: por ejemplo el Plan Más Vida de la provincia de Buenos Aires.

28 Se trata de programas asistenciales nacionales, implementados luego de la última crisis Argentina del 2001-2002 de transferencia de ingresos que condicionan el pago de una suma fija al cumplimiento de ciertas condicionalidades impuestas a la mujer jefa de hogar o la madre de familia. Véase ELA (2009) para una descripción de su alcance y análisis de sus condiciones.

29 Los programas de transferencias de ingresos han recibido críticas desde un enfoque de derechos debido a la total ausencia de perspectiva de género en su diseño e implementación, como es el caso del Programa Familias. También se señala que dicha política contradice las recomendaciones del Comité 
Asimismo, otra de las grandes críticas que se han efectuado a los programas de transferencia de ingresos se vincula con un mito que debiera desterrarse: una política pública no puede "salvar" a una generación bajo el costo de reforzar responsabilidades de cuidado en las mujeres exclusivamente. En consecuencia, es importante reconocer que para satisfacer las necesidades de los niños y los jóvenes es necesario hacer lo mismo con las generaciones adultas a cargo del cui$\mathrm{dado}^{30}$. Al mismo tiempo, no pareciera existir comprobaciones empíricas de que las condicionalidades sean efectivas por sí mismas: si bien las evaluaciones de programas muestran un impacto positivo en el estado de salud y el acceso a la educación de niños y niñas, no es posible atribuir el resultado al efecto de las mismas condicionalidades. En rigor, algunos estudios muestran efectos similarmente positivos en programas de transferencia de dinero que no imponen condiciones a las madres titulares del beneficio ${ }^{31}$.

Al tratarse de programas sociales asistencialistas, sujetos a manejos discrecionales y clientelares, poco se avanza en el sentido de promover un mayor acceso a la justicia. En rigor, la normativa del Programa Familias remarcó, hasta el año 2007, como condicionalidad para la incorporación del/la titular del beneficio, la firma de una carta-compromiso en la cual el/la titular se hace responsable de las obligaciones estipuladas. Dicha carta señalaba la renuncia de la titular a la posibilidad de efectuar reclamos de cualquier tipo en el caso que, por diversas circunstancias, se deje de ser beneficiario del programa. En otros términos: se "comprometía" a las madres beneficiarias que ante una baja en el plan no pudieran ejercer el derecho de reclamo, haciéndolas renunciar anticipadamente a su derecho de formularlo (CELS, 2007).

\section{El cuidado de adultos mayores}

Diversas investigaciones han señalado que el envejecimiento de la población y el aumento de "personas de edad" -frecuentemente denominados adultos mayores- y "personas dependientes" 32 , constituye un fenómeno demográfico de gran

de las Naciones Unidas para el seguimiento de la Convención para la Eliminación de Todas las Formas de Discriminación de la Mujer (CEDAW, por sus siglas en ingles) con respecto a evitar la perpetuación de visiones estereotipadas acerca del papel de mujeres y hombres y de prestar un apoyo efectivo a la potencialidad política y económica de la mujer (véase CELS, 2007).

30 Cf. Serrano, 2005.

31 Minujín et al., 2007.

32 El vocablo "personas de edad" refiere a dos categorías bien diferentes en términos sociales y económicos. Por una parte, personas "retiradas autónomas", en plena posición de medios físicos y mentales y, por otra, las personas "dependientes" cuya autonomía funcional es reducida y dependen de recursos exteriores (atención de la salud, cuidados familiares, lugar de residencia) para tener buenas condiciones de vida. Teniendo en cuenta que las mujeres son más longevas, éstas se encuentran más a menudo como "dependientes" ya que "el paso del tiempo lejos de suavizar las diferencias de género y las diferencias sociales las tiende a acentuar y las personas son portadoras, de alguna manera, de las características de su vida activa, luego de haber acopiado recursos o bien por el contrario, acumulado pérdidas" (Aguirre, 2004: 235). Así, por ejemplo, el análisis de las relaciones de género muestra que mujeres y varones no ingresan al mercado laboral en igualdad de condiciones, debido principalmente a la dificultad que enfrentan 
magnitud que demanda una revisión profunda de las políticas públicas en general y de los sistemas de seguridad social en particular. El envejecimiento de la población ha multiplicado los deberes familiares relacionados con el cuidado y atención de los y las adultos mayores. Argentina, junto con Uruguay, se encuentran en el grupo de países de envejecimiento avanzado: Uruguay es el país que presenta el porcentaje más alto de población mayor de 60 años (17\%) seguido por Argentina (13\%) (Aguirre, 2004).

El envejecimiento de la población traslada nuevas responsabilidades de cuidado a las familias, sin que aún se hayan dado respuestas integrales por parte de las políticas públicas, por ejemplo avanzando en nuevas formas jurídicas que apunten a regular el cuidado de personas mayores y que trasciendan las regulaciones laborales para trabajadores asalariados. En aquellos hogares en los cuales no se cuenta con recursos económicos para solventar servicios o una infraestructura de cuidado para adultos/as mayores (servicio doméstico remunerado, "cuidadoras", agentes sanitarias, geriátricos, centros de día, centros recreativos para la tercera edad) son precisamente las mujeres las principales responsables de proveer cuidado a los miembros de su familia, también en el caso de los adultos mayores.

De acuerdo con los datos analizados por Pautassi (2008), la información empírica refleja la situación de vulnerabilidad de los adultos mayores: únicamente tiene cobertura de una obra social o plan de salud privado el 77\% de la población mayor de 60 años. Además, se encuentra sin ninguna cobertura de salud el 23\% de la población de la misma franja etária, según datos del Censo Nacional de Población del 2001. Por otra parte, las reiteradas crisis en el Instituto Nacional de Servicios Sociales para Jubilados y Pensionados han dejado sin atención a un importante número de adultos mayores ${ }^{33}$.

A este escenario de vulnerabilidad y de inadecuadas respuestas por parte de las políticas públicas se suman los problemas del sistema de previsión social. Como destaca Marco (2004), es preciso tener en cuenta que no toda la población en edad de jubilación se encuentra en las mismas condiciones, como tampoco lo está el segmento de la población que en la actualidad debería reunir fondos para jubilarse. Estas disparidades, en general, se relacionan con los niveles de ingreso, con la inserción en el mercado laboral o la no pertenencia a él, con los perfiles ocupacionales y con el sexo de los ciudadanos. Además, debe considerarse que las mujeres son más longevas que los varones y que pasan más tiempo inactivas y sin un ingreso proveniente de su trabajo. Por lo tanto, deberían pasar una mayor can-

las mujeres para articular el trabajo productivo (en el mercado de empleo) con las responsabilidades familiares (el cuidado de las personas dependientes del hogar). A su vez, las trayectorias laborales se ven condicionadas por mercados de empleo que segregan a las mujeres en determinadas ocupaciones. Estas situaciones tienen un impacto directo en las condiciones de vida de las mujeres ya que determina un acceso diferencial al sistema de protección frente a la vejez (pensiones, jubilaciones).

33 La crisis institucional ha llegado al extremo de presentar frecuentes irregularidades en los servicios que prestan los geriátricos privados a la obra social de los jubilados y pensionados. En este contexto, la corrupción y desaprensión en el cuidado de esta población vulnerable ha sido más que notoria, dejando sin ninguna protección a las y los adultos mayores (Pautassi, 2008). 
tidad de años de su vida en calidad de pensionadas. Sin embargo, esto no sucede en la práctica, ya que no son las principales beneficiarias del sistema previsional ${ }^{34}$.

En rigor, en Argentina los déficits y problemas intrínsecos de los sistemas de capitalización individual son numerosos -baja cobertura, evasión de los propios aportantes- $\mathrm{y}$ en los años que se mantuvieron vigentes incrementaron las brechas en términos de género en materia previsional. El aumento significativo de la tasa de actividad femenina del último periodo no se ha traducido en mayores aportes al Sistema Integrado de Jubilaciones y Pensiones (SIJyP). Más específicamente, las mujeres representan el 34,5\% de los aportantes y el 64\% de quienes tienen jubilación o pensión.

Las medidas adoptadas en el último periodo en torno al sistema previsional, entre las cuales se encuentran los aumentos en los haberes previsionales y la reforma del régimen jubilatorio -que absorbió, sustituyó y eliminó el régimen de capitalización por el de reparto, a cargo de la Administración Nacional de Seguridad Social (Anses) ${ }^{35}$ - representan una mejora sustantiva para un sector de los adultos mayores. Sin embargo, esta última reforma no se hizo como una medida correctiva de las inequidades de género, como se evidencia en el hecho que no se ha evaluado el impacto diferencial que la misma tiene entre varones y mujeres. Si bien el régimen de reparto es más favorable para las mujeres -debido a que no establece una estrecha relación entre el aporte efectivo y el beneficio a percibir, sino que el beneficio se calcula en base a un promedio de los últimos salarios percibidos, entre otras cuestiones-, las disparidades de género siguen sin ser consideradas a la luz de los sistemas previsionales.

La otra vía para acceder a algún tipo de protección social es el sistema nacional de pensiones no contributivas, que se aplica según la contingencia y el tipo de pensión: falta de cobertura previsional alternativa, ausencia de subsidios de cualquier tipo, falta de ingresos laborales, riesgo médico-social, vejez, soledad, ausencia del progenitor o desempleo de éste para las madres de familia numerosa, desempleo, presencia y cantidad de hijos menores, incapacidad permanente y desamparo institucional (Pautassi, 2008) ${ }^{36}$.

Bajo la órbita del Ministerio de Desarrollo Social de la Nación fue creado el Programa "Adulto Mayor Más", dirigido a aquellos adultos mayores de 70 años

34 Cabe recordar que los resultados de la moratoria previsional que se aplicó en Argentina en el año 2007 son un claro ejemplo de cómo las brechas en el mercado laboral se reproducen en el sistema previsional: el $87 \%$ de las personas que se presentaron a la moratoria previsional fueron mujeres, con una edad promedio de 72 años y las tres cuartas partes de ellas no contaba con ningún beneficio jubilatorio previo. Esta medida tuvo un impacto altamente significativo sobre la ampliación de la cobertura previsional (ELA, 2009).

35 El 20 de noviembre de 2008 por Ley 26.495 se dejó sin efecto el régimen de capitalización individual, retornando todos los fondos al manejo estatal a partir de la unificación en el Régimen Previsional Público. Al realizar este reemplazo se garantizó a los afiliados al anterior régimen de capitalización privada idéntica cobertura y tratamiento que la brindada por el régimen previsional público en cumplimiento del mandato previsto por el artículo 14 bis de la Constitución Nacional.

36 En rigor, el sistema otorga siete tipos de beneficios: (i) por vejez; (ii) por invalidez; (iii) a madres de siete o más hijos; (iv) a familiares de desaparecidos; (v) a excombatientes de la guerra de Malvinas; (vi) otorgados por leyes especiales; (vii) "graciables" otorgados por el Congreso de la Nación. 
que no cuentan con amparo previsional o no contributivo. Este programa ha sido objeto de numerosas críticas a la luz del enfoque de derechos, entre otros motivos, por tratarse de una pensión a título personal (cuando el cónyuge titular fallece cae también el beneficio) y por la exigencia de una residencia mínima continuada de cuarenta años para personas extranjeras ${ }^{37}$.

Ante este escenario cabe alertar acerca de los problemas que presentarán los años venideros ante el creciente envejecimiento de la población. En este sentido debiera quedar en claro que la situación de los adultos mayores es el resultado de las inequidades acumuladas a lo largo de todo el ciclo vital y que requiere de la adopción de políticas públicas integrales para su resolución.

De no revertirse estas tendencias puede aumentar la desprotección, en especial de aquellos adultos que no cuentan con familias o que las mismas no puedan asumir su rol de responsables principales del cuidado. Nuevamente, la consideración del derecho universal al cuidado es lo que abre el espectro de la incorporación en los ordenamientos legales de adultos mayores como receptores de cuidado por parte de los/las trabajadores/as activos/as (Pautassi, 2008).

\section{El derecho al cuidado en los tribunales de justicia de la ciudad de Buenos Aires}

\subsection{EL CASO}

En marzo de 2008 la Cámara de Apelaciones del fuero Contencioso Administrativo y Tributario de la Ciudad de Buenos Aires confirmó la sentencia que condenaba al Gobierno de la Ciudad a cesar en su omisión de asegurar y garantizar el acceso a la educación inicial de los niños y niñas de 45 días a 5 años de edad ${ }^{38}$. La causa había sido iniciada en diciembre de 2006 por la organización Asociación Civil por la Igualdad y la Justicia (ACIJ) contra el Gobierno de la Ciudad de Buenos Aires (GCBA) por falta de vacantes en el nivel preinicial e inicial.

La demanda fue iniciada en el marco del Programa por la Igualdad Educativa que ACIJ desarrolla desde el año 2006, inspirados en la idea de que en contextos de amplia desigualdad socioeconómica, la educación básica obligatoria es una de las herramientas fundamentales del Estado para neutralizar el impacto de las diferencias sociales e igualar las oportunidades de los individuos. En este marco, y considerando que el Estado asume claros compromisos igualitarios en materia de educación, la organización comenzó a analizar la forma en que el gobierno de la ciudad distribuía sus recursos educativos.

37 Para un análisis del Programa "Adulto Mayor Más" desde un enfoque de derechos, véase CELS (2004).

38 Tanto el fallo de primera instancia como el fallo resuelto por la Cámara de Apelaciones del fuero Contencioso Administrativo y Tributario de la Ciudad de Buenos Aires se encuentran disponibles en la página de internet de la Asociación Civil por la Igualdad y la Justicia (www.acij.org.ar). 
En su demanda contra el Gobierno de la Ciudad, ACIJ presentó evidencias que señalaban que durante los ciclos lectivos del periodo comprendido entre los años 2002 a 2006, el GCBA incumplió su obligación de asegurar el acceso a la educación inicial de los niños y niñas de la Ciudad, aun cuando tuvo a su disposición recursos económicos para incrementar la cantidad de vacantes ofrecidas y no los utilizó: en el año 2006 hubo 6.047 niños y niñas que no tuvieron su vacante mientras que durante los 5 años analizados coexistieron inexplicablemente un presupuesto sub-ejecutado con falta de vacantes.

Los fundamentos a partir de los cuales ACIJ sustenta la acción se desarrollan a lo largo de tres ejes fundamentales. En primer lugar, la omisión de la Ciudad vulnera el derecho a la educación y sus distintas dimensiones por: la importancia de la educación inicial en el desarrollo de niños y niñas; las relaciones entre el acceso a ese nivel educativo y el rendimiento escolar en los primeros años; la oportunidad irreparable que significa acceder a la educación inicial; y por la contención que ello implica para niños y niñas cuyos padres trabajan además de la oportunidad de padres y madres de trabajar o buscar empleo, mientras sus hijos e hijas se encuentran al cuidado de la escuela. En segundo lugar, la omisión del Gobierno vulnera el principio de autonomía personal, que exige que las personas puedan contar con los bienes necesarios que les permitan la elección y materialización de ideales personales y planes de vida basados en ellos. La falta de vacantes en el sistema inicial vulnera este principio ya que es fundamental para el desarrollo de las capacidades que permitirán ulteriormente a los niños y niñas la adopción y materialización de sus planes de vida, de acuerdo con sus deseos y perspectivas. Por último, el derecho a la igualdad de estos niños y niñas se ve vulnerado por la falta de acceso equitativo a los dos primeros.

De acuerdo con el relato de los jueces de la Cámara de Apelaciones, el GCBA argumentó en su descargo que "no existe omisión lesiva imputable a su parte", menciona que se está ejecutando una serie de obras en establecimientos escolares y hace alusión a obras en construcción, ampliación o refacción con indicación de la inversión efectuada por proyecto para el año 2007. En rigor, de acuerdo con la valoración efectuada por los jueces del caso, los informes presentados por el GCBA fueron contradictorios e, incluso, confirmaron hechos aducidos en la demanda.

\subsection{LAS NORMAS EN JUEGO}

La Constitución de la Ciudad Autónoma de Buenos Aires sancionada en octubre de 1996 dedica su Libro Primero a los Derechos, Garantías y Políticas Especiales, entre ellas, la Educación. ${ }^{39}$ En particular, el artículo 24 dispone que:

39 Otras políticas especiales previstas en el Título Segundo del Libro Primero de la Constitución son: salud; ambiente; hábitat; cultura; deporte; seguridad; igualdad entre varones y mujeres, niños, niñas y adolescentes; juventud; personas mayores; personas con necesidades especiales; trabajo y seguridad social; consumidores y usuarios; comunicación; economía, finanzas y presupuesto; función pública; ciencia y tecnología; y turismo (desarrolladas en los artículos 17 a 59 de la Constitución de la Ciudad). 
"La Ciudad asume la responsabilidad indelegable de asegurar y financiar la educación pública, estatal, laica y gratuita en todos los niveles y modalidades, a partir de los cuarenta y cinco días de vida hasta el nivel superior, con carácter obligatorio desde el preescolar hasta completar diez años de escolaridad, o el periodo mayor que la legislación determine".

Claramente, los términos del artículo 24 primer párrafo de la Constitución de la Ciudad permiten afirmar que existe una directriz muy clara del constituyente y el hecho de incluirla como una de las "políticas especiales" permite sostener la pertinencia de discutir judicialmente la existencia de políticas que cumplan con el mandato constitucional. Pero además de la norma presente en la Constitución local existen otras disposiciones contenidas en la Constitución Nacional, en los tratados internacionales de derechos humanos y aun en leyes nacionales y locales que protegen con claridad (aunque en términos más generales) el derecho a la educación:

El derecho a la educación aparece, aunque con referencia a la educación primaria, ya en el texto de la Constitución histórica $\left(\operatorname{art} .5^{\circ} \mathrm{CN}\right)$. Del mismo modo, la Ley Fundamental se ha referido a la instrucción general y universitaria, para lo cual confirió competencia al Congreso (art. 75 inc. $18 \mathrm{CN}$ ). En lo que interesa al caso de autos, tales directrices han sido profundizadas mediante la incorporación de instrumentos internacionales de derechos humanos (art. 75 inc. 22 CN). En primer lugar, la Declaración Americana de los Derechos y Deberes del Hombre consagra el derecho a la educación de toda persona, inspirada en los principios de libertad, moralidad y solidaridad humanas (art. XII). Por otra parte, el artículo 26 de la Declaración Universal de Derechos Humanos establece el derecho de toda persona a la educación, orientado hacia el pleno desarrollo de la personalidad humana y del sentido de su dignidad, así como al respeto de los derechos humanos y las libertades fundamentales [...] En esa misma línea se inscribe el artículo 13 del Pacto Internacional de Derechos Económicos Sociales y Culturales, disposición que ha sido interpretada por el Comité de Derechos Económicos, Sociales y Culturales por conducto de la Observación General $N^{\circ} 13$. Del mismo modo, otras normas del Derecho Internacional de los Derechos Humanos se refieren al derecho a la educación, poniendo el énfasis en aspectos particulares como la no discriminación, en particular la basada en la raza o etnia (v. art. 5 inc. d ap. v. de la Convención Internacional sobre Eliminación de Todas las Formas de Discriminación Racial) o en el sexo (v. art. 10 de la Convención sobre la Eliminación de Todas las Formas de Discriminación contra la Mujer). En este contexto, y debido a su especificidad, conviene recordar que la Convención sobre los Derechos del Niño, también dotada de jerarquía constitucional, reconoce el derecho del niño a la educación e indica una serie de medidas progresivas tendientes a asegurar la efectividad de este derecho (art. 28). 
E1 derecho al cuidado: ¿Una nueva cuestión social ante los tribunales de justicia...

[...] En este orden de ideas... resulta pertinente recordar otras normas, de nivel infraconstitucional, que también se refieren a este derecho. En tal sentido, cabe señalar que la Ley $N^{\circ} 26.061$ de Protección Integral de los Derechos de los Niños, Niñas y Adolescentes establece en su artículo 15 el derecho de éstos a la educación pública y gratuita [...] Por otra parte, la Ley $\mathrm{N}^{\circ} 26.206$ (Ley de Educación Nacional) se refiere específicamente a la educación inicial (arts. 18 y ss.), a la que considera "una unidad pedagógica", que "comprende a los/as niños/as desde los 45 (cuarenta y cinco) días hasta los 5 (cinco) años de edad inclusive, siendo obligatorio el último año" (art. 18). Asimismo, se establece la obligación de universalizar los servicios educativos para los/as niños/as de 4 (cuatro) años de edad (art. 19). La norma nacional consagra la responsabilidad del Estado nacional, de las provincias y de la Ciudad Autónoma de Buenos Aires, en cuanto a: "a) Expandir los servicios de educación inicial; [...] c) Asegurar el acceso y la permanencia con igualdad de oportunidades, atendiendo especialmente a los sectores menos favorecidos de la población" (art. 21). [Fallo de Primera Instancia $]^{40}$.

Según el entendimiento de los jueces que intervinieron en el caso, el derecho conculcado, de acuerdo con las normas invocadas en las sentencias, sería el derecho a la educación. Las sentencias del juez de Primera Instancia y de la Cámara de Apelaciones omiten hacer referencia a otros instrumentos internacionales que desarrollan el derecho al cuidado desde perspectivas más amplias y que hubieran permitido un análisis más exhaustivo de las implicancias de proveer una cantidad adecuada de vacantes para niños y niñas a partir de los 45 días de edad.

Como sostiene Pautassi (2007), si se considera el principio de interdependencia consagrado en la Declaración y Programa de Acción de Viena de 1993, se puede considerar que el derecho al cuidado -tanto considerando a la persona como receptor o como dador de cuidado- integra el conjunto de los derechos universales de derechos humanos consagrados en los diversos instrumentos internacionales, a pesar de no estar explícitamente nominado como tal.

La Observación General N 6 del Comité del Pacto Internacional de Derechos Económicos, Sociales y Culturales es esclarecedora al señalar que de los derechos económicos, sociales y culturales de las personas mayores ha derivado el derecho al cuidado de este grupo vulnerable. Posteriormente, el derecho al cuidado para las personas mayores se incorporó de manera explícita en el artículo 17 del Protocolo de San Salvador, al establecer que "toda persona tiene derecho a protección especial durante su ancianidad. En tal cometido, los Estados partes se comprometen a adoptar de manera progresiva las medidas necesarias a fin de llevar este derecho a la práctica...”.

De manera similar, la Convención Internacional de Derechos del Niño, citada por las sentencias que se analizan, contiene disposiciones que exceden el derecho

$40 \quad$ El fallo se encuentra disponible en www.acij.org.ar 
a la educación en una de las dimensiones vinculadas con este caso. El artículo 18 inciso 1 establece que corresponde al Estado garantizar "el reconocimiento del principio que ambos padres tienen obligaciones comunes en lo que respecta a la crianza y el desarrollo del niño [...] su preocupación principal será el interés superior del niño..." para reafirmar en el inciso 3 del mismo artículo la vinculación de infraestructura del cuidado a la condición laboral de los padres: "los Estados partes adoptarán todas las medidas apropiadas para que los niños cuyos padres trabajan tengan derecho a beneficiarse de los servicios e instalaciones de guarda de niños para los que reúnan las condiciones requeridas..." (Convención Internacional de Derechos del Niño, articulo 18).

Recientemente, los gobiernos de los países participantes de la décima Conferencia Regional sobre la Mujer de América Latina y el Caribe ${ }^{41}$, representados por ministras/os y funcionarias/os de los mecanismos de adelanto de las mujeres del más alto nivel, firmaron un documento conocido como el "Consenso de Quito", que contiene el plan de acción al que se comprometieron los gobiernos nacionales de la región. En particular, el documento establece en su punto xxvii que los gobiernos acuerdan "Adoptar las medidas necesarias, especialmente de carácter económico, social y cultural para que los Estados asuman la reproducción social, el cuidado y el bienestar de la población como objetivo de la economía y responsabilidad pública indelegable" ${ }^{\prime 2}$.

El compromiso expresamente asumido por el gobierno de Argentina en el marco del Consenso de Quito pone de manifiesto la centralidad del derecho al cuidado, concebido como un fin en sí mismo pero también como medio indispensable para el pleno desarrollo de las familias y la promoción y permanencia de las mujeres en la vida política y social.

Entonces, como se desarrolla más adelante, una adecuada interpretación del artículo 24 de la Constitución de la Ciudad de Buenos Aires, en consonancia con otros objetivos planteados por el constituyente, permite una lectura más amplia del derecho a la educación que invocan los jueces, que claramente había sido vulnerado en el caso impulsado por ACIJ.

\subsection{Los ARgumentos del Poder Judicial (y otros ARgumentos POSIBLES)}

El caso presentado por ACIJ ante los tribunales de la Ciudad de Buenos Aires es sumamente relevante en materia de acceso al sistema educativo en condiciones de igualdad y se inscribe en la incipiente y promisoria tendencia de algunos tribunales de reconocer la justiciabilidad de los derechos económicos y sociales de la población vulnerable.

41 La conferencia se celebró en la ciudad de Quito, Ecuador, del 6 al 9 de agosto de 2007.

42 Cf. Décima Conferencia Regional sobre la Mujer de América Latina y el Caribe, 6 al 9 de agosto del 2007, Quito, Ecuador. (cf. http://www.cepal.org/publicaciones) 
De los distintos elementos de los fallos de primera y segunda instancia, a los fines de este artículo interesa destacar dos aspectos. En primer lugar, la lectura que la Cámara de Apelaciones hace de los diferentes aspectos del derecho a la educación, que fueran puestos de manifiesto en el planteamiento de ACIJ. En segundo lugar, las medidas dictadas por el tribunal a los efectos de asegurar el cumplimiento de la sentencia.

La Cámara fundamenta su decisión en las normas que consagran el derecho a la educación, tanto en el plano internacional como local (la Constitución Nacional, la Constitución de la Ciudad, leyes nacionales y leyes locales), sin referencias al cuidado como derecho. La sentencia se detiene en distintos aspectos del derecho a la educación y sus implicancias para los sectores más desfavorecidos de la población.

\section{Argumenta la Cámara}

Debe resaltarse que la educación inicial debe analizarse desde un doble aspecto: por un lado, la educación en sí misma de los primeros años de vida y, por el otro, un ámbito de cuidado y protección fuera del ámbito familiar. La dimensión, pues, que se asigna a la educación inicial, y a diferencia del resto de las etapas de la educación de los menores, es que en su faz protectoria intenta revertir situaciones de abandono infantil y alejarlos de situaciones de peligro (Sentencia de la Cámara de Apelaciones).

La segunda dimensión que aborda la Cámara se vincula, a su entender, con una función asistencial particularmente dirigida a los sectores más vulnerables:

Señala la doctrina que “...la función originaria de la educación inicial, de carácter asistencial, ha influido notablemente en el desarrollo de la misma, hasta el punto que podría afirmarse que continúa vigente en casi todos los sistemas escolares del mundo, en paralelo con la otra función, más reciente, de orientación propiamente educativa. La dualidad de funciones presente en esta etapa se constata en la existencia, en la mayoría de los países, de un doble tipo de programas, distintos en función del objetivo que cumplen" 43 (Sentencia de la Cámara de Apelaciones).

Con citas de documentos vinculados con los debates en torno de la Ley de Educación Nacional, la Cámara refuerza el rol de la familia en la educación temprana de niños y niñas, al suscribir la idea de que sólo en ausencia de ésta (o ante sus 'deficiencias') deberá intervenir el Estado mediante políticas que permitan brindar igualdad de oportunidades a niños y niñas en situaciones diversas:

43 La cita recogida por la sentencia de la Cámara de Apelaciones corresponde a Egido Gálvez, Inmaculada, (1999) "La educación inicial en el ámbito internacional. Situación y perspectiva en Iberoamérica y en Europa", Revista Ibero-Americana, No 22, Organización de Estados Iberoamericanos. 
En este entendimiento, se observó que "La familia tiene una responsabilidad fundamental en esta etapa, cumpliendo su propio rol educativo en el desarrollo inicial de niños y niñas y proveyéndolos de una serie de condiciones básicas para su progresiva participación en el ámbito educativo. En muchos casos y como consecuencia de las condiciones adversas que existen en contextos sociales signados por la desigualdad, el cumplimiento de esta función se ve resentido. Es entonces cuando la educación infantil impulsada por el Estado asume la función de prevenir las desigualdades de origen social que se traducen en falta de adaptación al ámbito educativo o pueden conducir al fracaso escolar. Cuanto más tempranamente sean atendidas estas inequidades mayor será la posibilidad de prever sus consecuencias educativas y sociales"44. Estas pautas que orientan la educación inicial fueron consideradas al tratar la nueva Ley de Educación Nacional.

"Las transformaciones sociales y particularmente las que afectan a la organización familiar explican la rápida expansión de servicios educativos desde edades muy tempranas. La población de cero a cuatro años hoy tiene un acceso muy desigual a instituciones educativas. Para crear condiciones de igualdad en el acceso será preciso expandir la oferta de atención temprana a la niñez con una oferta educativo-integral según las exigencias de cada edad. Si bien asumimos que la educación inicial es un derecho de los niños y no de los padres, no podemos olvidar que es necesario garantizar las condiciones para que los padres y madres de esos niños y niñas puedan ofrecer a sus hijos las máximas posibilidades de desarrollo"45 (Sentencia de la Cámara de Apelaciones).

A pesar de que entre los argumentos esbozados por ACIJ -según surge de la propia sentencia de la Cámara- se menciona la relevancia que tienen los servicios educativos en el nivel inicial sobre la vida laboral de la familia toda vez que permiten a los progenitores trabajar o buscar empleo (lo que repercute directamente en la situación económica de los niños y niñas), los jueces de la Cámara no avanzan en ese sentido. En lugar de desarrollar la noción del derecho al cuidado, lo que hubiera permitido una comprensión más amplia de la omisión del Gobierno de la Ciudad y su posterior vinculación con otros aspectos de los sujetos del cuidado, los jueces apoyan su decisión en la innegable relevancia que la escuela tiene a los efectos asistenciales de una importantísima cantidad de familias porteñas, según la propia información brindada por la Ciudad:

Es dable poner de relieve que el propio Gobierno de la Ciudad -a través de su presentación de fs. 818 emanada de la Dirección General de Niñez y Adolescencia del Ministerio de Derechos Humanos y Sociales- reconoce que la población beneficiaria de los jardines maternales "...son las niñas o niños menores de 4 años pertenecientes a familias en situación de pobreza y/o vulnerabilidad social residentes en la Ciudad de Buenos Aires". Más aún, afirma que junto con

44 La cita recogida por la sentencia de la Cámara de Apelaciones corresponde a Documento para el Debate Ley de Educación Nacional. 
las actividades educativas -en el caso de la jornada completa- se brinda desayuno, almuerzo y merienda; atención y seguimiento médico y odontológico, entre otros beneficios. Teniendo en cuenta el valor intrínseco del derecho a la educación, en particular, del derecho a la educación inicial, es necesario analizar si el Gobierno de la Ciudad de Buenos Aires garantiza dicho derecho con el alcance que las normas nacionales, internacionales, y en especial locales, le confieren. Es decir, si la demandada asegura el derecho a la educación de los niños de entre 45 días y 5 años de edad, derecho que además debe hacerse efectivo considerando la adopción de las medidas adecuadas a tal fin "hasta el máximo de los recursos de que se disponga", tal como lo establece el Pacto Internacional de Derechos Económicos, Sociales y Culturales (Sentencia de la Cámara de Apelaciones).

El segundo aspecto que interesa destacar de la sentencia bajo análisis se vincula con la importancia de asegurar el cumplimiento de lo ordenado por el tribunal. Como sostuvo el juez,

la elucidación del planteo de la actora -en cuanto a la existencia de una omisión estatal- no presenta complejidad alguna. En cambio, sí puede presentar alguna complejidad la implementación de la solución al problema, ya que existe un número de alternativas que, en principio, debe elegir la Administración. Pero no parece que, remitiendo a la actora a los procedimientos ordinarios, tales dificultades puedan ser evitadas. Como se verá, será en la etapa de ejecución de sentencia en que será necesario procurar vías adecuadas para la mejor implementación de lo resuelto (Sentencia de la Cámara de Apelaciones).

Esta consideración del proceso de ejecución de la sentencia, como una etapa de suma relevancia, nos remite a la consideración de los remedios judiciales y la necesaria creatividad e innovación que el activismo jurídico (en particular, respecto de los derechos económicos y sociales) requiere del Poder Judicial y de su deseable y necesaria interacción (véase Bergallo, 2005).

Los intercambios entre funcionarios/as y reclamantes pueden darse como consecuencia de soluciones "dialogadas", dispuestas en el marco de procesos judiciales o en instancias administrativas, y son particularmente relevantes para la resolución de casos complejos donde la demanda no se agota en la aplicación directa de una norma y la dimensión del caso excede los intereses directos de las partes involucradas, tradicionalmente consideradas ${ }^{46}$.

45 La cita recogida por la sentencia de la Cámara de Apelaciones corresponde a Documento para el Debate Ley de Educación Nacional.

46 La Corte Suprema de Justicia de la Nación por ejemplo, tomó una iniciativa de este tipo en el caso "Verbitsky, Horacio s/habeas corpus", resuelto el 3 de mayo de 2005, en el que se discutían las condiciones de encierro de las personas privadas de libertad en la provincia de Buenos Aires. Para un análisis de este caso, véase CELS (2008) ya que el Centro de Estudios Legales y Sociales (CELS) fue la organización de derechos humanos de Argentina impulsora de este caso. 
En el caso que se analiza en este trabajo, la Cámara de Apelaciones confirmó lo dispuesto por el juez de primera instancia con respecto a las medidas que deberían tomarse para fiscalizar el cumplimiento de la orden de cesar en la omisión de asegurar y garantizar el acceso a la educación inicial. Para ello, el juez dispuso que las medidas de ejecución de la sentencia consistirían en una actividad de carácter instrumental que permitan al tribunal vigilar el cumplimiento de la obligación constitucional:

A los fines de asegurar el cumplimiento de la sentencia, la demandada deberá:

(a) Presentar en el término de treinta días hábiles de quedar firme la sentencia, el detalle de las obras en ejecución (tanto del Ministerio de Educación como del Ministerio de Derechos Humanos y Sociales), cuya realización fue oportunamente informada en estos autos, discriminadas por Distrito Escolar, debiendo precisar: dirección, nombre del establecimiento, cantidad de aulas previstas, cantidad de niñas y niños que podrá albergar cada establecimiento, estado de la obra y fecha de finalización.

(b) Presentar en el término de 90 (noventa) días hábiles desde que quede firme la sentencia, los proyectos de obras nuevas necesarias para satisfacer la demanda educativa correspondiente a niños y niñas de entre 45 (cuarenta y cinco) días y 5 (cinco) años, discriminados por Distrito Escolar. Deberán asimismo indicarse los plazos de ejecución de las obras, el cual no deberá exceder del ciclo lectivo 2010.

(c) Presentar en el tribunal antes de que finalice el presente ciclo lectivo (2007) un proyecto que especifique claramente las medidas que adoptará para asegurar que a partir de 2008 los niños de entre 45 (cuarenta y cinco) días y 5 (cinco) años puedan acceder a establecimientos de nivel inicial. Con ese fin deberá efectuar un seguimiento de la situación de los niños que -según los listados ya acompañados en autos- se encontraron en lista de espera durante el presente año, sin haber podido hallar un establecimiento educativo, debiendo informar la solución que adoptará en cada uno de esos casos. Ello, sin perjuicio de los nuevos inscritos, a fin de asegurar la atención escolar de los niños de esas franjas etárias (Fallo de Primera Instancia).

Para dar cumplimiento a la orden judicial, en abril de 2008 el Ministerio de Educación porteño presentó públicamente un plan de construcción de jardines de infantes a pesar de que la Ciudad había apelado el fallo de la Cámara cuestionando la competencia de los tribunales de justicia para intervenir en la definición de las políticas sociales ${ }^{47}$.

El caso examinado ilustra la exitosa intervención de una organización civil que recurre al derecho como herramienta de transformación social, en este caso, en beneficio de la población más vulnerable de la ciudad de Buenos Aires, con el

$47 \quad \mathrm{Al}$ momento de la redacción de este artículo el caso se encuentra pendiente de la resolución del Tribunal Superior de Justicia de la Ciudad de Buenos Aires, máxima instancia judicial en el ámbito de la ciudad. 
objetivo de garantizar su acceso a la educación inicial en condiciones de igualdad. Sin embargo, como se ha puesto de manifiesto a partir de los argumentos a los que efectivamente recurrieron los jueces (y aquellos que podrían haber invocado), parece apropiado indagar acerca de las posibilidades de recurrir al activismo judicial como medio para promover la incorporación del derecho al cuidado en términos amplios, entre aquellos que reciben la tutela judicial.

En esa dirección, a partir del caso examinado, en el próximo apartado abordaremos el rol que pueden desempeñar diversos actores sociales con vistas a la utilización de las estrategias legales y de litigio de interés público para canalizar demandas en lo que se refiere al derecho al cuidado.

\section{Actores sociales e intervención judicial en las políticas de cuidado}

Es clara la necesidad de hacer efectivas políticas de universalización y obligatoriedad del acceso al nivel preinicial e inicial de educación con miras a la promoción de una mayor igualdad en su acceso y en las trayectorias educativas de niños/as. Al mismo tiempo, es preciso avanzar en materia de una infraestructura de cuidado de calidad, garantizando el derecho a los progenitores de contar con el apoyo del sistema educativo. En este contexto, a partir del caso iniciado por ACIJ, la vía judicial parece haberse constituido en uno de los medios a través de los cuales puede demandarse la acción del Estado en esta materia.

Este tipo de planteos son justiciables, en la medida en que los alcances de la norma y la finalidad a alcanzar aparecen indicadas con una razonable precisión. En otras palabras, lo justiciable es la determinación de si existe o no una omisión de implementar una política pública en esta materia. Por otra parte, cabe reconocer a los restantes poderes constituidos una razonable laxitud en cuanto a los medios que elijan para alcanzar esos fines (Fallo de Primera Instancia).

Ante la clara justiciabilidad del derecho consagrado constitucionalmente, ¿en qué condiciones podría replicarse esta demanda por la implementación de las "políticas especiales" previstas en la Constitución de la Ciudad? Como sostiene Abramovich (2006), la debilidad de las instituciones democráticas de representación y el desgaste de los espacios tradicionales de mediación social y política que se profundizó en Argentina en particular, a partir de la década del noventa, contribuyeron a trasladar al poder judicial algunos conflictos colectivos que antes eran negociados en otros espacios ${ }^{48}$. Por medio de nuevos mecanismos procesales de representación de intereses colectivos se busca establecer temas de discusión de la agenda social, cuestionar los procesos de definición y ejecución de las políticas públicas, sus contenidos e impactos (cuando éstos

48 Gherardi (2009) analiza el rol (muchas veces desaprovechado) de la administración pública como garante del acceso a la justicia en la protección de los derechos sociales. 
existen), o cuestionar la ausencia de políticas específicas de competencia de los poderes políticos.

El caso que ilustra este artículo introduce una forma novedosa de plantear uno de los aspectos vinculados con el derecho al cuidado a través del activismo judicial. Aun cuando no se han explorado en toda su potencialidad los argumentos vinculados al derecho al cuidado, restringiéndose al análisis del derecho a la educación, el discurso de los jueces permite alentar ciertas esperanzas respecto de su protección. En este caso, la demanda fue planteada por una organización no gubernamental integrada por abogados y abogadas, dedicada a la defensa de los derechos de los grupos más desfavorecidos de la sociedad y el fortalecimiento de la democracia en Argentina. Ahora bien, ¿qué otros actores sociales podrían impulsar acciones de interés público en torno a distintos aspectos del derecho al cuidado ${ }^{49}$ ?

El fallo comentado restringe la interpretación del artículo 24 de la Constitución de la Ciudad al ámbito de la educación. Sin embargo, la interpretación de esta norma en consonancia con otros derechos protegidos por la misma Constitución como el derecho al cuidado de personas mayores (artículo 41), a la protección integral de la familia (artículo 37, última parte) y a la promoción de la igualdad entre varones y mujeres fomentando la integración de estas últimas a las actividades productivas mediante el estímulo de "la modificación de los patrones socioculturales estereotipados" (artículo 38), requiere una interpretación más comprensiva de todos los derechos e intereses en juego.

Sólo en la medida en que estas obligaciones dispuestas por los y las constituyentes sean comprendidas, como la indelegable responsabilidad de la Ciudad (en este caso, pero también de la Nación en los temas de su competencia) ${ }^{50}$ de diseñar e implementar políticas integrales de cuidado (para menores, mayores, personas con necesidades especiales), podrá superarse la concepción actual que relega el cuidado a la esfera privada, sobrecargando las responsabilidades familiares que recaen fundamentalmente en las mujeres.

En Argentina la literatura reciente da cuenta de muchas y variadas experiencias exitosas en el uso de las estrategias judiciales para promover la defensa de los derechos, no sólo por parte de organizaciones de la sociedad civil sino también por parte de grupos activistas, profesionales, instituciones académicas, organizaciones de mujeres y asociaciones sindicales ${ }^{51}$.

¿Qué se necesita para que tales instituciones y organizaciones se involucren en acciones tendientes a la plena efectividad de políticas públicas que atiendan las diferentes dimensiones de la problemática del cuidado?

Cada una de estas agrupaciones y organizaciones podrían reconocer el interés particular que el impulso de acciones legales para promover el derecho al cui-

49 Este interrogante no se plantea en términos procesales, es decir, buscando evaluar qué organizaciones, instituciones o personas estarian legitimadas procesalmente para iniciar acciones legales.

50 Argentina es un país federal donde coexisten instituciones nacionales y locales, con competencia para regular distintos aspectos legales y de las políticas publicas.

51 Véanse los trabajos incluidos en Abramovich y Pautassi (2009) y los casos referidos en CELS (2008), Bergallo (2006). 
dado tiene para sí mismas, para sus integrantes y para la población objeto de sus respectivas formas de intervención: adecuadas provisiones de cuidado favorecen el pleno desarrollo y la autonomía de las principales responsables del cuidado; permiten el pleno ejercicio de los derechos de las mujeres trabajadoras y, fundamentalmente, permiten socializar una responsabilidad hasta ahora privatizada en las familias y delegada casi exclusivamente en las mujeres. Una adecuada infraestructura de cuidado para menores, adultos mayores y personas con necesidades especiales ayudaría a superar la desigualdad implícita en esa atribución de responsabilidad.

Luego de una primera generación de casos en los que había -en ocasionescierta distancia entre los actores, los impulsores y los beneficiarios de los casos judiciales, la experiencia indica que las mayores probabilidades de éxito se presentan en aquellos planteos en los que hay una vinculación sólida entre los "beneficiarios" y el caso en sí mismo. Para un adecuado seguimiento del proceso judicial y luego de la ejecución de la sentencia, los actores sociales no deben estar desconectados de los actores que participan en la arena jurídica, sino que estos últimos deben ser una manifestación de los primeros (los actores sociales) (CELS 2008). Esta es la vinculación que requiere fortalecimiento para que el pleno reconocimiento y vigencia del derecho al cuidado pueda ser tomado como parte de las luchas de las organizaciones, movimientos y sectores sindicales.

Para avanzar en esa agenda, en primer lugar, es necesario difundir la concepción del cuidado como un derecho protegido como tal en las constituciones e instrumentos internacionales, cuestionando al cuidado como parte de las responsabilidades privadas que deben ser resueltas de manera exclusiva por las familias, naturalizando la deserción del Estado en esa área.

En segundo lugar, es importante mejorar la articulación entre los diferentes actores e instituciones que tienen la capacidad técnica y la experiencia en la utilización del litigio estratégico como herramienta para promover sus agendas políticas y aquellos otros grupos que han desarrollado las herramientas conceptuales que permiten argumentar las violaciones de derechos implícitas en la ausencia de las distintas formas de políticas de cuidado. Gloppen (2008) analiza los recursos y las estrategias que permiten que grupos desaventajados planteen y reclamen por el pleno ejercicio de sus derechos sociales ante los tribunales de justicia, superando las barreras y obstáculos conocidos para el acceso a la justicia. La autora señala que un factor clave es la capacidad asociativa del grupo que formula el reclamo: su capacidad para convocar a otros, organizar movilizaciones, aunar esfuerzos con los especialistas en las estrategias legales. Esto requiere que las organizaciones especializadas acerquen los argumentos, interpretaciones, estudios e información empírica en general a quienes se encuentren en condiciones de sustanciar un litigio estratégico. Y que, en ese proceso, ambas partes adquieran capacidades que recíprocamente les permitan mantener esa asociación y, al mismo tiempo, enriquecer sus respectivas competencias para el futuro.

El activismo judicial en la forma de litigios de interés público requiere de varias estrategias combinadas para ser efectivo: no sólo es preciso una estrategia 
jurídica adecuada y la capacidad técnica de llevarla adelante sino que también necesita una política de alianzas sólidas entre diversos actores e instituciones comprometidas con la problemática que se aborda y una estrategia comunicacional efectiva que logre colocar el tema en la agenda pública, promoviendo un debate social amplio que permita explorar la diversidad y riqueza de los intereses involucrados ${ }^{52}$.

\section{Reflexiones finales}

Sin ignorar las objeciones que para algunos sectores despierta la intervención del poder judicial en causas en las que se discuten cuestiones vinculadas con políticas públicas $^{53}$, lo cierto es que hay experiencias exitosas que muestran las ventajas estratégicas que en algunas ocasiones representa el recurso al Poder Judicial como forma de politizar el derecho y exigir su cumplimiento.

Bergallo (2006) repasa el uso que las mujeres y sus organizaciones en Argentina han hecho del reclamo judicial, de manera individual o colectiva, en temas vinculados con la discriminación por sexo y las respuestas que han obtenido de los tribunales de justicia. La autora concluye que el litigio ha sido subutilizado como herramienta para avanzar en el respeto de los derechos de las mujeres, en parte por haber priorizado otras estrategias sociales y políticas, pero también por motivos diversos que incluyen las trabas que enfrentan las mujeres y sus organizaciones al intentar acceder al servicio de justicia; la escasa penetración del discurso feminista en la educación de operadores jurídicos, de ámbitos profesionales y en el Poder Judicial; la reducida participación de profesionales del derecho en las organizaciones de mujeres y la insuficiente integración de una perspectiva de género más completa en las organizaciones de derechos humanos y de defensa de derechos civiles.

Es evidente la necesidad imperiosa de hacer efectivas politicas de universalización y obligatoriedad de las instancias educativas iniciales, con miras a la promoción de una mayor igualdad, no sólo en el acceso a la educación sino también en las trayectorias educativas de niños y niñas. En la misma dirección, tales políticas públicas podrán redundar en una infraestructura de cuidado de calidad, garantizando el derecho de los progenitores a contar con el apoyo del sistema educativo para la articulación de sus responsabilidades familiares y laborales, con la activa participación y compromiso del Estado.

Sin embargo, las políticas públicas de cuidado que el Estado se ha obligado a implementar no deben limitarse a las políticas de atención o educación de los niños y niñas. De no implementarse inmediatamente políticas públicas universales

52 Sobre la importancia de articular las estrategias legales, politicas y comunicacionales, véase CELS (2008) y Jaramillo Sierra y Alfonso Sierra (2008).

53 Estas objeciones fueron destacadas y respondidas en varios documentos. Para una revisión general de los argumentos, ver Alegre (2007) y Gargarella (2008). 
e integrales que incorporen a los adultos mayores como receptores de cuidado, el envejecimiento de la población presentará en los años venideros importantes problemas puesto que la situación de este sector de la población es también el resultado de las inequidades acumuladas a lo largo de todo el ciclo vital.

De no revertirse estas tendencias, puede aumentar la desprotección en términos de acceso al derecho a cuidado (para niños, niñas, adultos mayores, personas con necesidades especiales de cuidado), en particular de aquellas personas que no cuentan con familias en posición de asumir un rol de principales responsables del cuidado.

La sentencia judicial impulsada por ACIJ analizada en este artículo restringe la interpretación de las garantías previstas en artículo 24 de la Constitución de la Ciudad de Buenos Aires al ámbito de la educación, y su violación es entendida, por lo tanto, exclusivamente como lesiva del derecho a la educación. Sin embargo, este artículo argumenta que la interpretación de esta norma en consonancia con otros derechos protegidos por la misma Constitución, como el derecho al cuidado de personas mayores, la promoción de la igualdad de oportunidades entre varones y mujeres y el fomento de la plena incorporación de la mujer en el empleo remunerado, requiere una interpretación comprensiva de todos los intereses en juego.

El cambio de paradigma que implica el reconocimiento del cuidado como derecho que comprende la existencia del derecho a cuidar, a cuidarse y a ser cuidado, constituye la nueva cuestión social, imprescindible para generar las condiciones para una sociedad más justa y para que la promesa de igualdad de oportunidades para mujeres y varones se encuentre más cerca de ser una realidad.

\section{Bibliografía}

ABRAMOVICH, VÍCTOR, 2006. "Acceso a la justicia y nuevas formas de participación en la esfera política". En Haydee Birgin y Beatriz Kohen (comp.), Acceso a la justicia como garantía de igualdad. Instituciones, actores y experiencias comparadas. Buenos Aires: Editorial Biblos, 59-82.

Abramovich, Víctor y COURTIS, CHRISTIAN. 2002. Los derechos sociales como derechos exigibles. Madrid: Trota.

Abramovich, VÍctor y PAUTASSI, LAURA (comp.). 2009. La revisión judicial de las politicas sociales. Estudio de casos en Argentina. Buenos Aires: Del Puerto editores.

Aguirre, Rosario. 2004. "Familias urbanas del Cono Sur: transformaciones recientes en Argentina, Chile y Uruguay”. En I. Arriagada; V. Aranda (comp.), Cambios en las familias en el marco de las transformaciones globales: necesidad de politicas públicas eficaces. Seminarios y Conferencias 42. Santiago de Chile: CEPAL, 225- 257.

Alegre, MARCElo, 2007. "Igualitarismo, Democracia y activismo judicial". En M. Alegre y R. Gargarella (coord.), El derecho a la igualdad. Buenos Aires: Lexis Nexos, 145-162.

ARRIAGADA, IRMA. 2004. "Estructuras familiares, trabajo y bienestar en América Latina". En I. Arriagada; V. Aranda (comp.), Cambios en las familias en el marco de las transformaciones globales: necesidad de políticas públicas eficaces. Seminarios y Conferencias 42. Santiago de Chile: CEPAL, 43-73. 
ASTElarRA, Judith. 2005. "Género, políticas conciliatorias entre los ámbitos productivo y reproductivo y presupuesto público". Ponencia presentada en la Reunión de Expertos del Fondo de Población de las Naciones Unidas. México: Fondo de Población.

Bergallo, PAOLA. 2005. "Justicia y experimentalismo: la función remedial del poder judicial en el litigio de derecho público en Argentina”, Trabajo presentado en el Seminario Latinoamericano de Teoría Constitucional (SELA). Buenos Aires: Editorial del Puerto.

Bergallo, PAOLA. 2006. "Igualdad de género: experiencias y perspectivas para su exigibilidad judicial”. En V. Abramovich; A. Bovino; C. Courtis (comp.), La aplicación de los tratados sobre derechos humanos en el ámbito local. La experiencia de una década, Buenos Aires: Del Puerto editores, 629-683.

BIRGIN, H. y GHERARDI N. 2008. "El acceso a la justicia como un derecho humano fundamental: retos y oportunidades para mejorar el ejercicio de los derechos de las mujeres". En A. Etchegoyen (cord.), Mujery Acceso a la Justicia. Conferencia 2008. Buenos Aires: APDH-AECID, 87-106.

Centro de Estudios Legales y Sociales (Cels). 2004. Derechos Humanos en Argentina, Informe 2004. Buenos Aires: Siglo XXI editores.

CENTRO De Estudios Legales y Sociales (CELS). 2007. Programa Familias por la inclusión social. Entre el discurso de derecho y la práctica asistencial, Cuaderno de Investigación y Análisis 4. Buenos Aires: CELS.

Centro de Estudios Legales y Sociales (CElS). 2008. La lucha por el derecho. Litigio estratégico y derechos humanos. Buenos Aires: Siglo XXI editores.

EQUiPO LATINOAMERICANO DE JUSTICIA Y GÉNERO. 2007. Cómo nos vemos las mujeres, Actitudes y percepciones de las mujeres sobre distintos aspectos de sus condiciones de vida. Buenos Aires: OXFAM-ELA.

EQUIPO LATINOAMERICANO DE JUSTICIA Y GÉNERO (ELJG). 2009: Informe sobre Género y Derechos Humanos en Argentina. Vigencia y respeto de los derechos de las mujeres (20052008), Buenos Aires: Editorial Biblos.

FolBre, NANCY. 2001. The Invisible Heart, Economics and Family Values. New York: The New Press.

Frone, Michael. R.; Russell, MARCiA; CoOPER, M. Lynee. 1992. "Antecedents and outcomes of work - family conflict: testing a model of the work-family interface" Journal of Applied Psychology 77 (1): 65-78.

GARGARELlA, ROBERTO. 2008. "Justicia y derechos sociales: lo que no dice el argumento democrático”. En R. Gargarella (coord.), Teoria y Crítica del Derecho Constitucional, Tomo II, Buenos Aires: Abeledo Perrot, 965-972.

GHERARDI, NATALIA. 2009. "La administración pública y el acceso a la justicia: una oportunidad para la materialización de los derechos sociales". En Víctor Abramovich; Laura Pautassi (comp.), La revisión judicial de las politicas sociales. Estudio de casos en Argentina. Buenos Aires: Del Puerto editores, 243-277.

GlOPPEN, SiRI. 2008. "Public Interest Litigation, Social Rights and Social Policy". En Anis A. Dani; Arjan De Haan (eds.), Inclusive States. Social Policy and Structural Inequalities, Washington: World Bank, 343-367.

JARAMILlO SiERRA, ISABEL; AlFONSO SIERRA, TATIANA. 2008. Mujeres, cortes y medios: la reforma judicial del aborto. Bogotá: Siglo del Hombre, Universidad de los Andes.

LISTER, RUTH. 1995. "Dilemmas in engendering citizenship". Economy and Society 24 (1): $1-40$.

MARCO, FlaVia. 2004. "Rasgos generales de los sistemas previsionales de capitalización individual y sus contextos laborales y demográficos". En Flavia Marco (coord.), Los sistemas de pensiones en América Latina. Santiago de Chile: CEPAL, 31-59. 
El derecho al cuidado: ¿Una nueva cuestión social ante los tribunales de justicia...

MARCO, FlaVIA. 2007. "El cuidado de la niñez en Bolivia y Ecuador: cuidado de algunos, obligaciones de todas", CEPAL, Unidad Mujer y Desarrollo. Santiago de Chile: CEPAL. Documento preparado para ser presentado en la X Conferencia Regional de la Mujer, Quito, Ecuador.

Maurino, Gustavo; Nino, Ezequiel, 2009. "Judicialización de Políticas Públicas de contenido social. Un examen a partir de casos tramitados en la ciudad de Buenos Aires". En Víctor Abramovich; Laura Pautassi (comp.), La revisión judicial de las políticas sociales. Estudio de casos en Argentina. Buenos Aires: Del Puerto editores, 173-206.

McClymont, Mary; Golub, Stephen (eds). 2001. Caminando hacia la Justicia. El trabajo en el área del derecho de los donatarios de la Fundación Ford en el mundo, Santiago de Chile: Fundación Ford.

Minujín, Alberto; Davidziuk, Alejandra; Delamónica, Enrique. 2007. "El Boom de las transferencias de dinero sujetas a condiciones. ¿De qué manera estos programas sociales benefician a los niños y niñas latinomericanos?”. Revista Salud Colectiva 3 (2): 121-131.

PAUTASSI, LAURA. 2007. El cuidado como cuestión social: una aproximación desde el enfoque de derechos, Serie Mujer y Desarrollo 87. Santiago de Chile: CEPAL.

PAUTASSI, LAURA. 2008. "Contingencias resignificadas. Nuevos desafíos de las políticas públicas para adultos mayores". Revista Derecho de Familia 40: 111-128.

PAUTASSI, LAURA; FAUR, ElEONOR; GHERARDI, NATALIA. 2004. Legislación laboral en seis paises latinoamericanos. Avances y omisiones para una mayor equidad, Serie Mujer y Desarrollo 56. Santiago de Chile: CEPAL.

PICCHIO, ANA. 1994. "El trabajo de reproducción, tema central en el análisis del mercado laboral”. En C. Borderías; C. Carrasco; C. Alemany (comp.), Las mujeres y el trabajo: rupturas conceptuales. Madrid: FUHUEM-ICARIA, 450-490.

REKOSH, EDWIN. 2005. “Quién define el interés público? Estrategias del derecho de interés público en Europa Centro-Oriental”. Sur, Revista Internacional de Derechos Humanos 2 (2): 181-193.

RODRÍGUEZ ENRÍQUEZ, CORINA. 2005. Macroeconomía y Economía del cuidado: un abordaje conceptual preliminar, Mimeo. Santiago de Chile: Centro de Estudios de la Mujer.

RODRÍGUEZ ENRÍQUEZ, CORINA. 2007. "La organización del cuidado de niños y niñas en Argentina y Uruguay”, Unidad Mujer y Desarrollo. Santiago de Chile: CEPAL. Documento preparado para ser presentado en la X Conferencia Regional de la Mujer, Quito, Ecuador.

Serrano, Claudia. 2005. La política social en la globalización. Programas de protección en América Latina, Serie Mujer y Desarrollo 70. Santiago de Chile: CEPAL.

TENTI FANFAni, EMILIO. 1995. La Escuela Vacía. Deberes del Estado y responsabilidades de la sociedad. Buenos Aires: Unicef/Losada.

TORns MARTIN, TERESA. 2005. "De la imposible conciliación a los permanentes malos arreglos". Cuadernos de Relaciones Laborales 23 (1): 15-33.

Tronto, JoAn, 2006. Vicious Circle of Privatized Caring. En Maurice Hamington; Dorothy Miller (eds.), Socializing Care: Feminist Ethics and Public Issues. Lanham, Maryland: Rowman \& Littlefield, 3-26

ZiBECCHI, CARLA. 2008. "Programas de transferencia de ingresos. ¿Más condicionalidades y menos derechos para las madres pobres? Un análisis en base a tres experiencias en América Latina". Revista Aportes Andinos 21 (http://www.uasb.edu.ec/padh_contenido.php). 